\title{
Germinação e vigor de sementes de Sapindus saponaria L. submetidas a tratamentos pré- germinativos, temperaturas e substratos
}

\author{
Germination and vigor of Sapindus saponaria L. seeds submitted pre-germinative treatments, temperatures \\ and substrates
}

\author{
Lucicléia Mendes de Oliveira' ${ }^{I}$ Riselane de Lucena Alcântara Bruno ${ }^{\text {II }}$ Katiane da Rosa Gomes da Silva ${ }^{\text {II }}$ \\ Valério Damásio da Mota Silva ${ }^{\text {III }}$ Cibele dos Santos Ferarri ${ }^{\text {II }}$ Givanildo Zildo da Silva ${ }^{\text {II }}$
}

\section{RESUMO}

Sapindus saponaria L. é uma árvore de grande porte distribuída especialmente na região Amazônica, sendo de grande importância para o reflorestamento de áreas degradadas, na construção civil e confecção de brinquedos. O objetivo dessa pesquisa foi testar tratamentos pré-germinativos para superar a dormência e avaliar o efeito da temperatura e do substrato na germinação das sementes de $\boldsymbol{S}$. saponaria. $O$ experimento foi conduzido em ambiente protegido e no Laboratório de Análise de Sementes (LAS) da Universidade Federal da Paraíba. Dois ensaios foram desenvolvidos, sendo no primeiro testados os seguintes tratamentos: imersão das sementes em ácido sulfúrico $\left(\mathrm{H}_{2} \mathrm{SO}_{4}\right)$ por $0,15,30,45$ e 60 minutos, analisando-se as variáveis: emergência e índice de velocidade de emergência, comprimento e massa seca de plântulas. No segundo ensaio foi avaliado o efeito das temperaturas $\left(25,20-30,30\right.$ e $\left.35^{\circ} \mathrm{C}\right)$ e substratos (areia, vermiculita e pó-de-coco) na germinação e no vigor das sementes. Pelos resultados constata-se que a imersão das sementes de $\boldsymbol{S}$. saponaria em ácido sulfúrico por 60 minutos é suficiente para superar a dormência acelerando e uniformizando a emergência das plântulas. A melhor condição para executar o teste de germinação é empregando temperatura constante de $30^{\circ} \mathrm{C}$ ou alternada de $20-30^{\circ} \mathrm{C}$ em substrato vermiculita ou apenas $30^{\circ} \mathrm{C}$ combinado com o substrato areia.

Palavras-chave: espécie florestal, saboneteira, dormência, tegumento impermeável.

\section{ABSTRACT}

Sapindus saponaria $L$. is a large tree distributed especially in the Amazon region is of great importance for the reforestation of degraded areas, construction and manufacture of toys. The aim of this study was to test pre-germination treatments to overcome dormancy and to evaluate the effect of temperature and substrate on seed germination of $\mathbf{S}$. saponaria. The experiment was conducted in a protected ambient and the Seed Analysis Laboratory (SAL), Universidade Federal da Paraíba. Two tests were developed, and tested first in the following treatments: seeds immersion in sulfuric acid $\left(\mathrm{H}_{2} \mathrm{SO}_{4}\right)$ for 0,15 , 30, 45 and 60 minutes, analyzing the variables: emergence and emergence speed index, length and dry mass of seedlings. In the second test, was evaluated the effect of temperatures (25, 20-30, 30 and $35^{\circ} \mathrm{C}$ ) and substrates (sand, vermiculite and coconut dust) on the germination and seed vigor. From the results it appears that the immersion of seeds of S. saponaria in sulfuric acid for 60 minutes is sufficient to overcome dormancy accelerating and standardizing the seedling emergency. The best conditions for testing germination using constant temperature of $30^{\circ} \mathrm{C}$ or alternating $20-30^{\circ} \mathrm{C}$ in vermiculite or only $30^{\circ} \mathrm{C}$ combined with the sand.

Key words: forest species, soap dish, dormancy, waterproof coat

\section{INTRODUÇÃO}

Sapindus saponaria L., pertencente à família Sapindaceae, conhecida popularmente como "sabão-desoldado”, saboneteira, sabão-de-macaco é uma espécie arbórea de distribuição marcante na região amazônica, podendo atingir até nove metros de altura, com grande importância para o reflorestamento de áreas degradadas, bem como, para exploração econômica de sua madeira empregada na construção civil, confecção de brinquedos

'Programa de Pós-graduação em Ciência e Tecnologia de Sementes, Universidade Federal de Pelotas (UFPEL), CP 354, 96001970, Pelotas, RS, Brasil. E-mail: lucicleia@biologa.bio.br. Autor para correspondência.

I"Departamento de Fitotecnia, Universidade Federal da Paraíba (UFPB), Centro de Ciências Agrárias (CCA), Areia, PB, Brasil.

IIIDepartamento de Solo e Engenharia Rural, UFPB, Areia, PB, Brasil. 
e o uso de suas sementes para o artesanato (LORENZI, 2000). No entanto, as suas sementes têm dormência imposta pela impermeabilidade do tegumento e ainda não foram definidas as condições ideais para o teste de germinação.

A dormência se caracteriza como um retardamento da germinação, pois mesmo com todas as condições favoráveis (umidade, temperatura, luz e oxigênio), as mesmas não germinam, no entanto, este fenômeno é utilizado pela planta como uma estratégia para que suas sementes germinem na época mais adequada ao seu desenvolvimento e com isso garantir a perpetuação da espécie (CARVALHO \& NAKAGAWA, 2000). Nesse sentido, os pesquisadores vêm desenvolvendo trabalhos com superação da dormência em sementes de várias espécies, tais como Caesalpinia ferrea Mart. Ex Tu. var. leiostachya Benth. em que a imersão da semente no ácido sulfúrico $\left(\mathrm{H}_{2} \mathrm{SO}_{4}\right)$ entre 18 a 20 minutos proporcionou maiores porcentagens e uniformidade de emergência (ALVES et al., 2009).

Segundo os tecnologistas de sementes, a germinação é definida como o desenvolvimento das estruturas essenciais do embrião, manifestando a sua capacidade para dar origem a uma plântula normal em condições ambientais favoráveis (BRASIL, 2009), sendo influenciada pela ação de diversos fatores, principalmente: disponibilidade de água, luz, temperatura, oxigênio e substrato, pois cada fator interfere de forma específica atuando sozinho ou em conjunto, no entanto, deve-se levar em consideração a sensibilidade das sementes de cada espécie a determinado fator (CARDOSO, 2004).

Dentre os fatores ambientais, a temperatura tem sido considerada um dos principais responsáveis pelo índice de velocidade e porcentagem final de germinação, por afetar especialmente a velocidade de absorção de água e a reativação das reações metabólicas essenciais aos processos de mobilização de reservas e a retomada de crescimento radicular (CARVALHO \& NAKAGAWA, 2000).

A temperatura adequada para a condução de testes de germinação foi definida para sementes de algumas espécies florestais, como exemplo citam-se as temperaturas constantes de 30 e $35^{\circ} \mathrm{C}$ para as sementes de Adenanthera pavonina L. (SOUZA et al., 2007).

O substrato também influencia na germinação, pois fatores como aeração, estrutura, capacidade de retenção de água, grau de infestação por patógenos, entre outros podem variar de acordo com o material utilizado, favorecendo ou prejudicando o processo germinativo. Na escolha do substrato deve ser levado em consideração fatores como tamanho da semente, sua exigência em relação à umidade e sensibilidade ou não à luz (FIGLIOLIA et al., 1993). Os tipos de substratos descritos nas Regras para Análise de Sementes são: papel toalha, papel filtro, papel mata-borão, areia e solo (BRASIL, 2009) para as espécies cultivadas e poucas florestais, no entanto são escassas as recomendações quanto ao tipo a ser empregado para as sementes de espécies florestais, destacando-se principalmente a vermiculita (FIGLIOLIA et al., 1993).

Diante do exposto, a presente pesquisa teve por objetivo avaliar os tratamentos pré-germinativos para superar a dormência e o efeito de diferentes temperaturas e substratos na germinação e vigor das sementes de $\boldsymbol{S}$. saponaria.

\section{MATERIAL E MÉTODOS}

O experimento foi conduzido no Laboratório de Análise de Sementes (LAS) do Centro de Ciências Agrárias da Universidade Federal da Paraíba (CCA/ UFPB), com sementes de $\boldsymbol{S}$. saponaria obtidas de frutos coletados em dez árvores matrizes no município de Cajazeiras - PB. Após o beneficiamento manual as sementes foram acondicionadas em recipientes plásticos e armazenadas em ambiente de laboratório a temperatura de $27 \pm 3^{\circ} \mathrm{C}$ e umidade relativa em torno de $85 \%$ durante quatro meses, quando foram utilizadas para instalação de dois ensaios.

\section{Ensaio - Tratamentos pré-germinativos}

As sementes foram imersas em ácido sulfúrico concentrado $\left(\mathrm{H}_{2} \mathrm{SO}_{4}\right)$ por $0,15,30,45$ e 60 minutos e a cada intervalo de tempo foram retiradas e lavadas em água corrente para a eliminação dos resíduos do ácido, sendo em seguida submetidas aos seguintes testes: emergência - as sementes provenientes dos respectivos tratamentos foram semeadas a uma profundidade de $2 \mathrm{~cm}$ em bandejas contendo areia, previamente esterilizada em autoclave $120^{\circ} \mathrm{C}$ por duas horas e mantidas em ambiente protegido, utilizando-se quatro repetições de 25. As contagens foram realizadas dos 11 aos 30 dias após semeadura, quando se observou a estabilização da emergência das plântulas, cujo critério utilizado foi o de plântulas com os cotilédones acima do substrato; índice de velocidade de emergência (IVE) - foram realizadas contagens diárias de plântulas emersas, juntamente com o teste de emergência, sendo o índice calculado conforme a fórmula proposta por MAGUIRE (1962); comprimento de plântulas - após a estabilização do teste de emergência as plântulas foram retiradas das bandejas, levadas ao laboratório para medições desde a coifa até o meristema apical, com os resultados expressos em centímetros; massa seca de plântulas - as plântulas medidas anteriormente foram colocadas em sacos do tipo Kraft e 
colocadas em estufa com ventilação forçada de ar regulada a $65^{\circ} \mathrm{C}$, até atingir peso constante; em seguida foram colocadas em dessecadores e, posteriormente, pesadas em balança analítica com precisão de $0,001 \mathrm{~g}$, sendo os dados expressos em g plântula ${ }^{-1}$.

O delineamento experimental utilizado foi inteiramente ao acaso, com seis tratamentos em quatro repetições, sendo os dados submetidos à análise de variância. Para os períodos de tempo de imersão das sementes no ácido sulfúrico foi realizada a análise de regressão polinomial, utilizando-se o programa WINSTAT. Para escolha do modelo de regressão que melhor se ajustasse aos dados observados levou-se em consideração o fato de o desvio da regressão ser não significativo e, o modelo de maior ordem ser de grau significativo e, por último, o valor do coeficiente de determinação $\left(\mathrm{R}^{2}\right)$.

\section{Ensaio - Temperaturas x substratos}

Após ter sido definido o melhor tratamento para superar a dormência das sementes testou-se a influência de temperaturas $\left(25,30,35\right.$ e $\left.20-30^{\circ} \mathrm{C}\right)$ e substratos (areia, vermiculita e pó-de-coco) na germinação e no vigor de sementes de $\boldsymbol{S}$. saponaria. A semeadura foi realizada a uma profundidade de $2 \mathrm{~cm}$ em bandejas plásticas para cada substrato esterilizado em autoclave a $120^{\circ} \mathrm{C}$ por duas horas e umedecidos com água destilada em quantidade equivalente a $60 \%$ da capacidade de campo. As bandejas foram mantidas em germinadores do tipo Biochemical Oxigen Demand (BOD) nas diferentes temperaturas, com fotoperíodo de 8 horas. As variáveis analisadas foram: germinação - as contagens foram realizadas aos 25 dias após semeadura, quando houve a estabilização da emergência das plântulas, cujo critério utilizado foi o de plântulas com os cotilédones acima do substrato e, os resultados foram expressos em porcentagem; primeira contagem - correspondeu ao número de plântulas emersas no $20^{\circ}$ dia após a semeadura, com os resultados expressos em porcentagem; índice de velocidade de germinação(IVG) - foi determinado mediante contagens diárias das plântulas emersas, a partir do $9^{\circ}$ até o 25ํㅡㄹ dia após a semeadura, sendo calculado através da fórmula proposta por MAGUIRE (1962). Também foram avaliados o comprimento total e a massa seca das plântulas conforme descrito no Ensaio I.

O delineamento experimental utilizado foi inteiramente ao acaso, com os tratamentos distribuídos em esquema fatorial $3 \times 4$ (substratos e temperaturas), em quatro repetições. Os dados foram submetidos à análise de variância pelo teste $\mathrm{F}$ e as médias comparadas pelo teste de Tukey a $5 \%$ de probabilidade, por meio do programa WINSTAT.

\section{RESULTADOS E DISCUSSÃO}

\section{Ensaio I}

A porcentagem de emergência (25\%) de plântulas oriundas das sementes não tratadas foi inferior em relação às sementes imersas no ácido sulfúrico por períodos mais prolongados. Dessa forma constatou-se que houve um aumento significativo na porcentagem de emergência das plântulas oriundas de sementes tratadas com ácido sulfúrico, cujos dados observados ajustaramse ao modelo quadrático (Figura 1A).

A ação do ácido sulfúrico no amolecimento do tegumento das sementes parece ser resultante da remoção da cutícula e exposição das camadas de macroesclerídeos, permitindo assim, graus de permeabilidade mais homogêneos (SANTARÉM \& ÁQUILA, 1995). Em estudo anatômico do tegumento de sementes maduras de $\boldsymbol{S}$. saponaria, ALBIERO et al. (2001) constataram que na testa havia muitas camadas de células, sendo assim a própria anatomia do tegumento da semente formada por diversas camadas de células pode ser uma limitação da absorção de água pela mesma, o que configura a dormência imposta pela impermeabilidade do tegumento.

Como o tegumento das sementes de $\boldsymbol{S}$. saponaria é muito espesso e esclerificado justifica-se um período longo de exposição ao ácido. O mesmo não foi observado em sementes de Parkia platycephala Benth, pois o período de 60 minutos no ácido acarretou algum dano nas sementes comprovado pela redução na porcentagem de emergência das plântulas (NASCIMENTO et al., 2009).

Na literatura alguns trabalhos demonstraram que em sementes com tegumento impermeável, tratamentos com ácido sulfúrico têm proporcionado bons resultados na superação desse tipo de dormência, conforme relatado por ALVES et al. (2006) para unidades de dispersão de Zizyphus joazeiro Mart. com a imersão entre os períodos de 74 e 115 minutos.

Os dados da primeira contagem de emergência (Figura 1B) ajustaram-se ao modelo quadrático, cujo aumento do tempo de imersão das sementes em ácido sulfúrico proporcionou o acréscimo de plântulas emersas. O maior tempo de imersão das sementes no ácido (60 minutos) foi o mais eficaz dentro dos períodos de tempo avaliados, provavelmente por ter promovido algum tipo de fissura no tegumento das sementes de $\boldsymbol{S}$. saponaria proporcionando a embebição, desencadeando o processo germinativo e posterior emergência das plântulas. Dados semelhantes foram encontrados para unidades de dispersão de Zizyphus joazeiro Mart. (ALVES et al., 2006), pois constatou-se que a imersão em ácido promoveu melhor expressão do vigor, avaliado pela primeira contagem de emergência. 

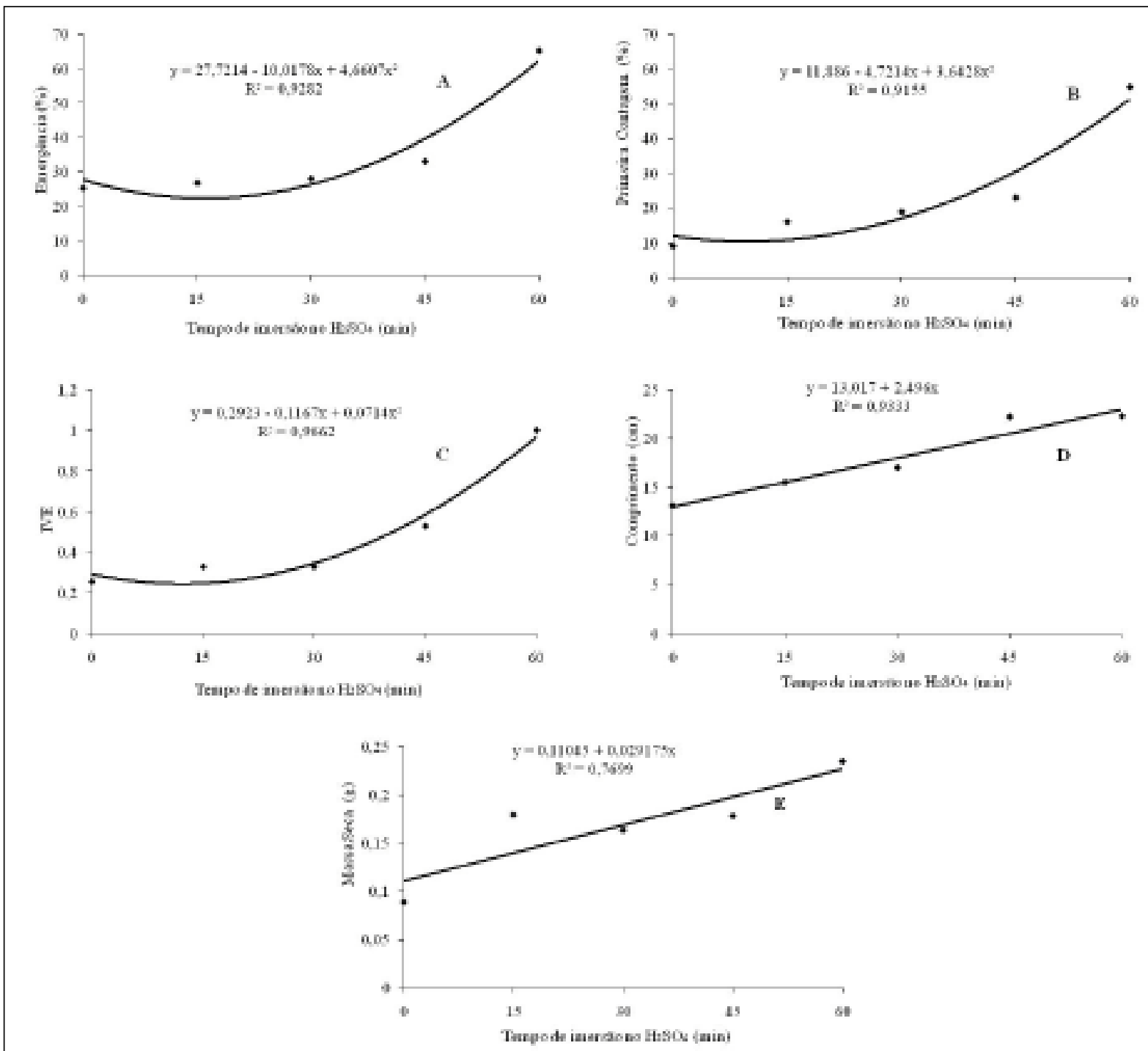

Figura 1 - (A) Emergência (\%), (B) Primeira Contagem de Emergência, (C) Índice de Velocidade de Emergência (IVE), (D) Comprimento de Plântulas (cm) e (E) Massa Seca de Plântulas (g) de $\boldsymbol{S}$. saponaria oriundas de sementes submetidas a diferentes períodos de imersão em ácido sulfúrico.

Em relação ao índice de velocidade de emergência (Figura 1C) observou-se desempenho similar àquele da emergência (Figura 1A), com maior valor quando as sementes foram submetidas ao período máximo de imersão estudado, de forma que se demonstrou satisfatório em predizer o vigor das sementes quando submetidas a um maior tempo de imersão em ácido. Resultados semelhantes para este teste foram obtidos com o mesmo tempo de imersão (60 minutos) para as sementes de Acacia mangium Willd. (RODRIGUES et al., 2008), uma vez que houve antecipação do processo germinativo, culminando com a emergência das plântulas.

O modelo linear foi o que melhor se ajustou aos resultados do teste de comprimento (Figura 1D) e massa seca de plântulas de $\boldsymbol{S}$. saponaria (Figura 1E), observando-se que estes testes também foram eficientes na distinção do vigor das sementes submetidas ao maior tempo de imersão no ácido sulfúrico para superar a dormência, uma vez que foram semelhantes aos dados de emergência.

O uso de metodologia para superar a dormência é fundamental para a propagação, conservação e manutenção da espécie, especialmente para os viveiristas, sendo referenciada na literatura (FOWLER \& BIANCHETTI, 2000) a utilização de escarificação manual com lixa n. 60 durante 30 segundos para sementes de $\boldsymbol{S}$. saponaria. Considerando-se que este método requer tempo e mão-de-obra, além de 
proporcionar desuniformidade de escarificação, a utilização de ácido sulfúrico pode ser uma alternativa viável, principalmente em termos de realização de pesquisas com a referida espécie.

\section{Ensaio II}

Para temperaturas e substratos foi verificada interação significativa $(\mathrm{P}<0,01)$ para todas as variáveis analisadas (Tabelas 1 e 2). A temperatura de $30^{\circ} \mathrm{C}$ para o substrato areia foi responsável pela maior porcentagem de germinação das sementes, enquanto no substrato vermiculita as melhores condições de germinação foram evidenciadas na temperatura constante de $30^{\circ} \mathrm{C}$ e alternada $20-30^{\circ} \mathrm{C}$ (Tabela 1 ), porém, o substrato pó-decoco influenciou negativamente o potencial germinativo independente da temperatura avaliada, provavelmente devido à dificuldade de retenção da água. Dados contraditórios foram verificados em sementes de Myracrodruon urundeuva Fr. All (PACHECO et al., 2006), pois o mesmo proporcionou resultados satisfatórios elevando a porcentagem de germinação; contudo, as sementes dessas duas espécies são de tamanho inferior às de $\boldsymbol{S}$. saponaria, o que possivelmente justifica o bom desempenho do pó-de-coco como substrato de germinação para as mesmas, uma vez que requerem menor volume de água disponível.

A temperatura de $35^{\circ} \mathrm{C}$ combinada com o substrato areia (Tabela 1) contribuiu para a maior velocidade de germinação das sementes, no entanto, prejudicou a capacidade de germinação a tal ponto que foi verificada uma grande quantidade de plântulas anormais. Esse fato pode estar diretamente relacionado à alta temperatura em que o teste foi conduzido, levando a aceleração dos processos metabólicos e ocasionando danos celulares. Segundo CAMARA et al. (2008) em sementes de Parkia pendula (Willd.) Benth. ex Walp também foi observada a redução da porcentagem de germinação em temperaturas a partir de $35^{\circ} \mathrm{C}$.
De acordo com os dados da tabela 2, não foi verificada diferença estatística para o comprimento de plântulas nas temperaturas testadas combinadas com os substratos areia e vermiculita, exceto a temperatura constante de $25^{\circ} \mathrm{C}$, onde ocorreram os menores valores. Porém, a vermiculita foi responsável pelo melhor desenvolvimento das plântulas, provavelmente em razão do mesmo reter maior quantidade de água e com isso contribuir para o desempenho das mesmas.

Para a variável massa seca de plântulas foi verificado o mesmo comportamento em relação às temperaturas, porém, não houve diferença entre os substratos areia e vermiculita quanto à alocação de massa seca. Segundo SILVA et al. (2009) em sementes de Calotropis procera (Aiton) $\mathrm{R}$. Br. ocorreu desempenho semelhante quanto a massa seca de plântulas, no entanto, a areia proporcionou maior comprimento das plântulas que a vermiculita na temperatura constante de $30^{\circ} \mathrm{C}$. Segundo FERNANDES et al. (2006), a maior proporção de partículas pequenas no substrato diminui a porcentagem de germinação das sementes, tendo em vista a dificuldade de absorção de água pelas mesmas nos primeiros dias após a semeadura e, com isso prejudica a aeração para as raízes após a quebra da tensão superficial, de forma que possivelmente poderá limitar a disponibilidade de água para as raízes e interferir no crescimento.

Os resultados permitem inferir que as melhores condições para executar o teste de germinação para as sementes de $\boldsymbol{S}$. saponaria é utilizando a temperatura constante de $30^{\circ} \mathrm{C}$ ou alternada $20-30^{\circ} \mathrm{C}$ combinado com os substratos areia ou vermiculita, por outro lado foi observado que temperatura mais elevada $\left(35^{\circ} \mathrm{C}\right)$ é prejudicial ao desenvolvimento das plântulas, acarretando alta porcentagem de plântulas anormais, além disso, verificou-se que o substrato pó-de-coco é inviável para instalar o teste de germinação para essa espécie.

Tabela 1 - Germinação e índice de velocidade de germinação das sementes de $\boldsymbol{S}$. saponaria submetidas a diferentes temperaturas e substratos.

\begin{tabular}{|c|c|c|c|c|c|c|}
\hline \multirow{3}{*}{ Temperaturas $\left({ }^{\circ} \mathrm{C}\right)$} & \multicolumn{3}{|c|}{ 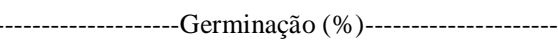 } & ------- & \multirow{2}{*}{\multicolumn{2}{|c|}{ - }} \\
\hline & \multirow[b]{2}{*}{ Areia } & \multirow[b]{2}{*}{ Vermiculita } & \multirow[b]{2}{*}{ Pó-de-coco } & \multirow[b]{2}{*}{ Areia } & & \\
\hline & & & & & Vermiculita & \multirow{2}{*}{$\frac{\text { Pó-de-coco }}{0,2 \mathrm{Bb}}$} \\
\hline 25 & $28 \mathrm{Bc}$ & $45 \mathrm{Ab}$ & $18 \mathrm{Bb}$ & $0,4 \mathrm{Bd}$ & $0,7 \mathrm{Ab}$ & \\
\hline $20-30$ & $50 \mathrm{Ab}$ & 63 Аа & $14 \mathrm{Bb}$ & $1,0 \mathrm{Ac}$ & 1,2 Аа & $0,2 \mathrm{Bb}$ \\
\hline 30 & $73 \mathrm{Aa}$ & 61 Аа & $27 \mathrm{Ba}$ & 1,3 Ab & 1,3 Аа & 0,4 Bb \\
\hline 35 & $31 \mathrm{Ac}$ & $18 \mathrm{Bc}$ & $31 \mathrm{Aa}$ & 1,8 Аа & $1,2 \mathrm{Ba}$ & 0,5 Ca \\
\hline CV (\%) & & 12,98 & & & 16,07 & \\
\hline
\end{tabular}

Médias seguidas pela mesma letra, maiúscula na linha e minúscula na coluna, não diferem entre si, pelo teste de Tukey a 1\%.

Ciência Rural, v.42, n.4, abr, 2012. 
Tabela 2 - Comprimento e massa seca de plântulas de $\boldsymbol{S}$. saponaria oriundas de sementes submetidas a diferentes temperaturas e substratos.

\begin{tabular}{|c|c|c|c|c|c|c|}
\hline \multirow[t]{2}{*}{ Temperaturas $\left({ }^{\circ} \mathrm{C}\right)$} & $---\cdot$ & & -------------S & \multicolumn{3}{|c|}{ 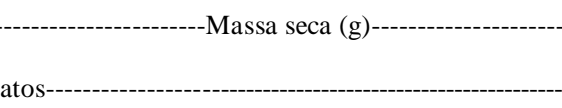 } \\
\hline & Areia & Vermiculita & Pó-de-coco & Areia & Vermiculita & Pó-de-coco \\
\hline 25 & $12,07 \mathrm{Bb}$ & $19,92 \mathrm{Ab}$ & $13,10 \mathrm{Ba}$ & $0,045 \mathrm{Ab}$ & $0,055 \mathrm{Ab}$ & 0,028 Аа \\
\hline $20-30$ & $20,35 \mathrm{Ba}$ & 25,32 Аа & $11,10 \mathrm{Ca}$ & 0,157 Аа & 0,144 Аа & 0,031 Ba \\
\hline 30 & $22,45 \mathrm{Ba}$ & $27,60 \mathrm{Aa}$ & $14,25 \mathrm{Ca}$ & 0,176 Аа & 0,163 Аа & 0,056 Ва \\
\hline 35 & $20,97 \mathrm{Ba}$ & 28,30 Аа & $10,47 \mathrm{Ca}$ & 0,183 Аа & 0,183 Аа & 0,044 Ва \\
\hline CV (\%) & & 12,32 & & & 24,70 & \\
\hline
\end{tabular}

Médias seguidas pela mesma letra, maiúscula na linha e minúscula na coluna, não diferem entre si, pelo teste de Tukey a 1\%.

\section{CONCLUSÃO}

A imersão das sementes em ácido sulfúrico por 60 minutos é suficiente para superar a dormência das sementes de $\boldsymbol{S}$. saponaria e a melhor condição para executar o teste de germinação é empregando a temperatura constante de $30^{\circ} \mathrm{C}$ ou alternada $20-30^{\circ} \mathrm{C}$ para o substrato vermiculita ou somente $30^{\circ} \mathrm{C}$ combinado com o substrato areia.

\section{REFERÊNCIAS}

ALBIERO, A.L.E. et al. Caracterização anatômica das folhas, frutos e sementes de Sapindus saponaria L. (Sapindaceae). Acta Scientiarum, Maringá, v.23, n.2, p.549-560, 2001. Disponível em: <http://periodicos.uem.br/ojs/index.php/ ActaSciBiolSci/article/viewArticle/2733>. Acesso em: 30 ago. 2011.

ALVES, E.U. et al. Ácido sulfúrico na superação da dormência de unidades de dispersão de juazeiro (Zizyphus joazeiro Mart.). Revista Árvore, Viçosa, v.30, n.2, p.187-195, 2006. Disponível em: $<$ http://www.scielo.br/scielo.php?script=sci_arttext\&pid=S010067622008000300003>. Acesso em: 30 ago. 2011. doi.org/ 10.1590/S0100-67622008000300003.

ALVES, E.U. et al. Escarificação ácida na superação da dormência de sementes de pau ferro (Caesalpinea ferrea Mart. ex Tu. var. leiostachya Benth.). Caatinga, Mossoró, v.22, n.1, p.37-47, 2009. Disponível em: <http://periodicos.ufersa.edu.br/revistas/ index.php/sistema/article/view/140>. Acesso em: 30 ago. 2011.

BRASIL. Ministério da Agricultura, Pecuária e Abastecimento. Regras para análise de sementes. Brasília: MAPA/ACS, Secretaria de Defesa Agropecuária, 2009. 395p.

CAMARA, C.A. et al. Caracterização morfométrica de frutos e sementes e efeito da temperatura na germinação de Parkia pendula (Willd.) Benth. ex Walp. Ciência Florestal, Santa Maria, v.18, n.3, p.281-290, 2008. Disponível em: <http:// redalyc.uaemex.mx/pdf/534/53418301.pdf $>$. Acesso em: 30 ago. 2011.
CARDOSO, V.J.M. Germinação. In: KERBAUY, G.B. Fisiologia vegetal. São Paulo: Guanabara Koogan, 2004. Cap.17, p.386-408.

CARVALHO, N.M.; NAKAGAWA, J. Sementes: ciência tecnologia e produção. 4.ed. Jaboticabal, SP: FUNEP, 2000. 588p.

FERNANDES, C. et al. Alterações nas propriedades físicas de substratos para cultivo de tomate cereja, em função de sua reutilização. Horticultura Brasileira, Brasília, v.24, n.1, p.9498, 2006. Disponível em: <http://www.scielo.br/ scielo.php?script =sci_arttext \& pid=S010205362006000100019>. Acesso em: 30 ago. 2011. doi.org/ 10.1590/S0102-05362006000100018.

FIGLIOLIA, M.B. et al. Análise de sementes. In: AGUIAR, I.B.; PIÑA-RODRIGUES, F.C.M. (Coords.). Sementes florestais tropicais. Brasília: ABRATES, 1993. p.137-174.

FOWLER, A.J.P.; BIANCHETTI, A. Dormência em sementes florestais. Colombo: EMBRAPA Florestas, 2000. 27p. (EMBRAPA Florestas. Documentos, 40).

LORENZI, H. Árvores brasileiras: manual de identificação de plantas arbóreas nativas do Brasil. 2.ed. Nova Odessa: Plantarum, 2000. 352p.

MAGUIRE, L.D. Speed of germination - aid in selection and evolution for seedling emergence and vigor. Crop Science, Madison, v.2, n.2, p.176-177, 1962.

NASCIMENTO, I.L. et al. Superação da dormência em sementes de faveira (Parkia platycephala Benth.). Revista Árvore, Viçosa, v.33, n.1, p.35-45, 2009. Disponível em: <http://www.scielo.br/ pdf/rarv/v33n1/v33n1a05.pdf>. Acesso em: 30 ago. 2011.

PACHECO, M.V. et al. Efeitos de temperaturas e substratos na germinação de sementes de Myracroduon urundeuva Fr. All (Anacardiaceae). Revista Árvore, Viçosa, v.30, n.3, p.359376, 2006. Disponível em: <http://www.scielo.br/pdf/rarv/v30n3/ a06v30n3.pdf $>$. Acesso em: 30 ago. 2011.

RODRIGUES, A.P.D.C. et al. Tratamentos para superar a dormência de sementes de Acacia mangium Willd. Acta Scientiarum Agronomy, Maringá, v.30, n.2, p.279-283, 2008. 
Disponível em: <http://periodicos.uem.br/ojs/index.php/ ActaSciAgron/article/viewArticle/1786>. Acesso em: 30 ago. 2011. doi: 10.4025/actasciagron.v30i2.1786.

SANTARÉM, E.R.; ÁQUILA, M.E.A. Influência de métodos de superação de dormência e do armazenamento na germinação de sementes de Senna macranthera (Colladon) Irwin \& Barneby (Leguminosae). Revista Brasileira Sementes, Brasília, v.17, n.2, p.205-209, 1995. Disponível em: <http://www.abrates.org.br/ revista/artigos/1995/v17n2/artigo14.pdf>. Acesso em: 30 ago. 2011.
SILVA, J.R. et al. Temperatura e substrato na germinação de sementes de flor-de-seda. Caatinga, Mossoró, v.22, n.1, p.175179, 2009. Disponível em: <http://redalyc.uaemex.mx/redalyc/ pdf/2371/237117625024.pdf>. Acesso em: 30 ago. 2011.

SOUZA, E.B. et al. Germinação de sementes de Adenanthera pavonina $\mathrm{L}$. em função de diferentes temperaturas e substratos. Revista Árvore, Viçosa, v.31, n.3, p.437-443, 2007. Disponível e $\mathrm{m}:<\mathrm{ht} \mathrm{t}$ p : / / w w w. s c i e l o.b r / scielo.php? script=s ci_arttext\&pid=S $0100-$ 67622007000300009>. Acesso em: 30 ago. 2011. 